\title{
ESPAÇAMENTO NA PRODUÇÃO DE ARROZ DE TERRAS ALTAS IRRIGADO NO CERRADO
}

Rogério Oliveira Menezes ${ }^{1}$, Carlos Alberto Da Silva Ferreira ${ }^{2}$, Alan Carlos de Oliveira Castro ${ }^{3}$, Matheus Vinicius Abadia Ventura ${ }^{3}$, Thales Caetano de Oliveira ${ }^{3}$, Germanna Gouveia Tavares ${ }^{3}$

${ }^{1}$ Faculdade Evangélica de Goianésia - FACEG, Goianésia, GO. ${ }^{2}$ Universidade Federal de Goias - UFG, Pós-Graduação em Fitossanidade, GO. ${ }^{3}$ Instituto Federal Goiano campus Rio Verde - IFGoiano, , Pós-Graduação em Ciências Agrárias Agronomia, GO. E-mail: agronomocarlos@yahoo.com.br

\section{RESUMO}

A produtividade do arroz de terras altas aumenta com o número de plantas por unidade de área até o ponto em que a competição intraespecífica por nutrientes, água, luz e outros fatores de produção limita o processo produtivo. $\mathrm{O}$ objetivo deste trabalho foi avaliar o efeito do espaçamento na produção da cultura do arroz de terras altas irrigado no cerrado. 0 experimento foi conduzido de maio a outubro do ano de 2015 em Goianésia - GO, na área experimental da Faculdade Evangélica de Goianésia. Foi testada a variedade BRS Primavera em quatro espaçamentos $(20,30,40$ e $50 \mathrm{~cm})$ entre linhas e densidade de 100 sementes por metro e utilizada irrigação por aspersão. O delineamento experimental utilizado foi em blocos casualizados, sendo quatro tratamentos com 3 repetições. Os resultados mostraram que o espaçamento de $30 \mathrm{~cm}$ entre linhas proporcionou maior produtividade na variedade BRS Primavera.

Palavras-chave: Oryza sativa L.; rizicultura; fitotecnia; produção vegetal.

\section{SPACE IN THE PRODUCTION OF HIGH RICE RICE IRRIGATED IN THE CLOSED}

\begin{abstract}
The productivity of upland rice increases with the number of plants per unit area to the point where intraspecific competition for nutrients, water, light and other factors of production limits the productive process. The objective of this work was to evaluate the effect of spacing on the production of highland rice irrigated in the brazilian savannas. The experiment was conducted from May to October of the year 2015 in Goianésia - GO, in the experimental area of the Evangelical Faculty of Goianésia. The BRS Primavera variety was tested in four spacings $(20,30,40$ and $50 \mathrm{~cm})$ between rows and density of 100 seeds per meter and used as sprinkler irrigation. The experimental design was in randomized blocks, with four treatments with three replicates. The results showed that the spacing of $30 \mathrm{~cm}$ between rows provided higher productivity in the BRS Primavera variety.
\end{abstract}

Keywords: Oryza sativa L.; rice growing; plant breeding; plant production.

\section{INTRODUÇÃO}

O arroz (Oryza sativa L.) é uma cultura de grande importância na alimentação da população mundial. Cultivado em todos os continentes, se tem na Ásia a maior concentração de cultivo, com destaque para a China e Índia, responsáveis por $30,24 \%$, 21,52\% da produção mundial, respectivamente (EPAGRI, 2015). No Brasil é um dos alimentos que compõem a cesta básica, constituindo-se em uma das principais fontes de calorias do brasileiro. Em decorrência disso, desempenha papel estratégico na solução de questões de segurança alimentar (SOSBAI, 2010).
O arroz de terras altas deixou de ser cultivado apenas nas áreas recém-desmatadas, onde geralmente se adota baixo nível de tecnologia, para participar de sistemas de produção mais tecnológicos, como nas áreas de produção de soja ou nas de integração lavourapecuária. A produtividade do arroz de terras altas se eleva com o número de plantas por unidade de área até o ponto em que a competição intraespecífica por nutrientes, água, luz e outros fatores de produção limita o processo produtivo (GUIMARÃES et al., 2003).

Campos (1991) avaliou o efeito do espaçamento e densidade de plantio sobre os 
componentes de redução da cultivar de arroz de sequeiro 'Guarani', concluindo que os espaçamentos de 50 e $60 \mathrm{~cm}$ e densidades de 40 e 60 sementes por metro linear foram os mais adequados para a produção de grãos.

Santos (1990), trabalhando com as cultivares tradicionais de sequeiro 'Guarani' e 'Araguaia', obteve maior produção sob aspersão para a "Guarani" no espaçamento de $30 \mathrm{~cm}$ entre linhas, e para Araguaia, o espaçamento de $40 \mathrm{~cm}$ entre linha propiciou a maior produtividade. Stone e Pereira (1994) estudaram o efeito da adubação em área irrigada por pivô central usando cultivares tradicionais e linhagens criadas para condições de sequeiro favorecido. Essas últimas produziram melhor em espaçamentos mais estreitos, $20 \mathrm{~cm}$ entre linhas, com uma maior absorção de nutrientes.

Desconsiderando-se o aspecto fitossanitários associados à susceptibilidade diferenciada das cultivares às doenças, aquelas menos perfilhadoras requerem na semeadura mais sementes por área (ARF et al., 2015). Por outro lado, um excessivo número de plantas $/ \mathrm{m}^{2}$ acarreta maior auto sombreamento, provocando um menor aproveitamento da luz solar e maior possibilidade de acamamento e susceptibilidade às doenças (SANTOS et al., 2014). Estas condições propiciam um microclima mais úmido, onde este favorece o desenvolvimento de doenças, como a brusone (Pyricularia oryzae Cav.), e aumentam a demanda da cultura por água, além do risco pela ocorrência de veranicos. Por outro lado, baixas populações induzem ao sub aproveitamento da área e à emissão de perfilhos tardios e improdutivos, indesejáveis na lavoura (GUIMARÃES et al., 2003).

Souza e Azevedo (1994) avaliaram o efeito dos espaçamentos de 20, 35, 50 e $65 \mathrm{~cm}$ entre linhas e densidades de 50, 75, 100 e 125 sementes por metro, com a cultivar 'Rio Paranaíba' em sistema de irrigação por pivô central. Pelos resultados, constataram maior produção de grãos quando utilizaram o espaçamento menor, $20 \mathrm{~cm}$ entre linhas, independente das densidades de semeadura utilizadas. Foram observadas também diferenças significativas quanto à altura de plantas entre a maior e menor população.

Portanto, objetivou-se avaliar o efeito do espaçamento na produtividade de arroz de terras altas, irrigado por aspersão.

MATERIAL E MÉTODOS
O experimento foi conduzido na segunda quinzena do mês de maio até outubro do ano de 2015 em Goianésia-GO, na área experimental da FACEG (Faculdade Evangélica de Goianésia), nas seguintes coordenadas geográficas: 15을 32 $\mathrm{S}$ de latitude e 49 12' W de longitude, a 640 m de altitude. Segundo a Köppen e Geiger (1928), a classificação do clima é Aw (clima tropical com estação seca de inverno), com temperatura média de $24.4^{\circ} \mathrm{C}$ e a pluviosidade média anual é de $1502 \mathrm{~mm}$.

O delineamento experimental utilizado foi em blocos casualizados, utilizando parcelas de $4 \times 4 \mathrm{~m}$, com 3 repetições. Foi testada a variedade BRS Primavera num latossolo vermelho amarelo distrófico em quatro espaçamentos (20, 30, 40 e $50 \mathrm{~cm}$ ) entre linhas e densidade de 100 sementes $/ \mathrm{m}$, ficando com o seguinte stand de 5.000 .000 plantas ha ${ }^{-1}$ a parcela de $20 \mathrm{~cm}, 30 \mathrm{~cm}$ 3.250 .000 plantas/ha, $40 \mathrm{~cm} 2.500 .00$ plantas/ha e $50 \mathrm{~cm} \mathrm{2.000.000} \mathrm{plantas} \mathrm{ha-1}$, sendo que. cada parcela apresentou $16 \mathrm{~m}^{2}$. As parcelas apresentaram uma variação no número de linhas de acordo com o espaçamento entre elas considerado em cada tratamento, de modo que a área de cada parcela não se alterasse.

Na semeadura, a adubação utilizada foi 400 $\mathrm{kg} \mathrm{ha}^{-1}$ da formulação 4-30-10 (NPK), e em torno de 45 dias após a semeadura foi realizado uma adubação de cobertura com aplicação de 200 kg $\mathrm{ha}^{-1}$ de 30-00-00. Foram aplicados produtos à base de tiofanato metílico e fipronil para tratamento de sementes, aplicação realizada na linha de semeadura antes da cobrição. Foi utilizada irrigação por aspersão a cada 2 dias na fase vegetativa, com lâmina média de $12 \mathrm{~mm}$ por irrigação. $\mathrm{Na}$ fase reprodutiva, 70 dias após emergência, a irrigação utilizada foi $30 \mathrm{~mm}$ a cada 2 dias, mantendo o solo sempre com umidade. A cultivar BRS Primavera apresentou florescimento aos 95 dias e ciclo de 135 dias.

Foi realizado controle de percevejos dos grãos na fase final de maturação. Os demais tratos culturais foram realizados de acordo com a necessidade da cultura de terras altas (UTUMI, 2008). A colheita foi realizada quando $2 / 3$ das panículas apresentaram recurvas e com a coloração característica da cultura. E assim foi colhido $1 \mathrm{~m}^{2}$ de cada parcela de forma aleatória.

Os caracteres avaliados foram: altura de planta na fase de maturação, número de panículas, massa de 1.000 grãos e rendimentos de grãos - os grãos obtidos após a colheita de cada parcela útil foram pesados e a produtividade 
de cada parcela foi expressa em $\mathrm{kg} \mathrm{ha}^{-1}$, após a correção da umidade para $13 \%$.

Os dados foram submetidos a análise de variância, e ao ser constatado a significância pelo teste $F$, as médias dos tratamentos foram submetidos ao teste de Scott-Knott ao nível de $5 \%$ de probabilidade.

\section{RESULTADOS E DISCUSSÃO}

Observou que o espaçamento de $30 \mathrm{~cm}$ entre linhas influenciou na produtividade e no número de panículas (Tabela 1 ). A produtividade alcançada nesse espaçamento pode ser atribuída ao número de panículas que também foram superiores aos demais. Os resultados foram semelhantes aos encontrados por Crusciol et al. (2000), que obtiveram maior produtividade e número de panículas para arroz de terras altas irrigadas por aspersão no espaçamento de $30 \mathrm{~cm}$ entre linhas.

Santos et al. (2002) obteve melhores resultados para plantio irrigado por aspersão utilizando espaçamentos de 30 ou $40 \mathrm{~cm}$ entre linhas para cultivares do tipo moderno/filipino (agulhinha). Segundo Carvalho et al. (2008) os componentes de produção de grãos mais influenciados pelos espaçamentos de semeadura são o número de panículas por $\mathrm{m}^{2}$, número de grãos por panículas e o espaçamento de $30 \mathrm{~cm}$ entrelinhas proporciona a maior produtividade de grãos, independente da densidade de semeadura. Os resultados diferem de Souza \& Azevedo (1994) que utilizando irrigação por pivô central obtiveram maior produtividade em espaçamentos de $20 \mathrm{~cm}$ entre linhas com um adensamento maior das plantas.

Tabela 1. Valores produtividade em grãos e número de panículas de arroz irrigado por aspersão, submetidos a diferentes espaçamentos.

\begin{tabular}{ccc}
$\begin{array}{c}\text { Espaçamento } \\
\text { entre linhas }(\mathrm{cm})\end{array}$ & $\begin{array}{c}\text { Produtividade em grãos } \\
\left(\mathrm{kg} \mathrm{ha}^{-1}\right)\end{array}$ & $\begin{array}{c}\mathrm{N}^{\circ} \text { de panículas } \\
\left.\text { (unidades ha }^{-1}\right)\end{array}$ \\
\hline 20 & $1916 \mathrm{c}$ & $393.667 \mathrm{~b}$ \\
30 & $3073 \mathrm{a}$ & $474.330 \mathrm{a}$ \\
40 & $2726 \mathrm{~b}$ & $325.677 \mathrm{c}$ \\
50 & $1863 \mathrm{c}$ & $308.000 \mathrm{c}$ \\
\hline CV (\%) & 13,50 & 15,33 \\
\hline
\end{tabular}

As médias seguidas pela mesma letra na coluna não diferem estatisticamente entre si. Foi aplicado o Teste de ScottKnott ao nível de $5 \%$ de probabilidade.

Os espaçamentos menores que $30 \mathrm{~cm}$ dificultam a realização de tratos culturais, além de proporcionar microclima favorável para patógenos. Segundo Santos et al. (2002) espaçamentos mais estreitos favorecem a incidência de doenças, sobretudo escaldadura das folhas (Xanthomonas albilineans (Ashby) Dowson).

A altura das plantas não diferiu significativamente, onde o maior resultado obteve $64 \mathrm{~cm}$ e 0 menor $57 \mathrm{~cm}$ de altura média (Tabela 2). Resultados semelhantes foram encontrados por Oliveira (1994), por Arf (1993) e Crusciol et al. (2000) onde a altura das plantas não foi influenciada pelos espaçamentos. Por outro lado, difere dos resultados encontrados por Souza e Azevedo (1994) que encontrou maior altura em espaçamentos maiores e menor altura em espaçamentos mais adensados trabalhando com irrigação via pivô central. 
Tabela 2. Valores de altura de plantas de arroz irrigado por aspersão, submetidos a diferentes espaçamentos.

\begin{tabular}{cc}
\hline Espaçamento $(\mathrm{cm})$ & Altura de planta $(\mathrm{cm})$ \\
\hline 20 & $57,0 \mathrm{a}$ \\
30 & $60,3 \mathrm{a}$ \\
40 & $64,3 \mathrm{a}$ \\
50 & $59,6 \mathrm{a}$ \\
\hline CV (\%) & 17,33
\end{tabular}

As médias seguidas pela mesma letra não diferem estatisticamente entre si. Foi aplicado o Teste de Scott-Knott ao nível de $5 \%$ de probabilidade.

A massa de 1.000 grãos não foi influenciada significativamente pelos tratamentos (Tabela 3), o que atesta os resultados obtidos por Crusciol et al. (2000), Souza e Azevedo (1994), Oliveira et al. (1998) e em parte com Santos et al. (2002), onde a massa de 1.000 grãos não foi influenciada pela densidade de semeadura, essa variação somente foi influenciada entre as cultivares que é uma característica peculiar de cada cultivar. Por outro lado, Arf (1993) obteve um aumento no peso de 1.000 grãos com a diminuição do espaçamento entre linhas, já Stone e Pereira (1994) constataram um aumento significativo no peso de 1.000 grãos, quando aumentaram o espaçamento entre linhas de plantio.

Tabela 3. Valores de massa de 1.000 grãos de arroz irrigado por aspersão, submetidos a diferentes espaçamentos.

\begin{tabular}{cc}
\hline Espaçamento $(\mathrm{cm})$ & Massa de 1.000 grãos \\
\hline 20 & $30,8 \mathrm{a}$ \\
30 & $31,1 \mathrm{a}$ \\
40 & $30,8 \mathrm{a}$ \\
50 & $30,5 \mathrm{a}$ \\
\hline CV (\%) & 2,59
\end{tabular}

As médias seguidas pela mesma letra não diferem estatisticamente entre si. Foi aplicado o Teste de Scott-Knott ao nível de $5 \%$ de probabilidade.

De modo geral, observou-se que o espaçamento de $30 \mathrm{~cm}$ entre linhas obteve um maior número de panículas e produtividade, diferindo dos demais tratamentos (Figura 1).

\section{CONCLUSÕES}

A cultivar BRS Primavera apresenta maior produtividade e maior número de panículas no espaçamento de semeadura de $30 \mathrm{~cm}$ entre linhas, irrigado por aspersão e em condições de Cerrado.

Os espaçamentos entre linhas de semeadura de $20,30,40$ e $50 \mathrm{~cm}$ em arroz de terras altas irrigado não interfere na altura das plantas e na massa de 1.000 grãos.

\section{REFERÊNCIAS}

ARF, O. 1993. Efeitos de densidade populacional e adubação nitrogenada sobre 0 comportamento de cultivares de arroz irrigado por aspersão. 1993. 63f. Tese (Doutorado) Faculdade de Engenharia de Ilha Solteira, Universidade Estadual Paulista, Ilha Solteira, 1993.

ARF, O.; RODRIGUES, R. A. F.; NASCENTE, A. S.; LACERDA, M. C. Espaçamento e adubação nitrogenada afetando o desenvolvimento do arroz de terras altas sob plantio direto. Revista Ceres, v. 62, n. 5, p. 475-482, 2015. https://doi.org/10.1590/0034737X201562050008

CAMPOS, V. C. Influência do espaçamento e densidade de semeadura sobre algumas características agronômicas e qualidade de sementes de arroz (Oryza sativa L.) de sequeiro, c.v. Guarani. 93f. 1991. Dissertação (Mestrado 
em Fitotecnia) - Escola Superior de Agricultura de Lavras, Lavras, 1991.

CARVALHO, J. A. D.; SOARES, A. A. REIS, M. D. S. Effect of sowing spacing and density on yield and production components of rice cultivar BRSMG Conai. Ciência e Agrotecnologia, v. 32, n. 3, p. 785-791, 2008. https://doi.org/10.1590/S141370542008000300012

CRUSCIOL, C. A. C.; MACHADO, J. R.; ARF, O.; RODRIGUES, R. A. F. Yield of upland rice cultivated under sprinkler irrigation as a function of row spacing and seed density. Pesquisa Agropecuária Brasileira, v. 35, n. 6, p. 1093-1100, $2000 . \quad$ https://doi.org/10.1590/S0100204X2000000600004

GUIMARÃES, C. M.; STONE, L. F.; SILVA, F. X. Espaçamento entre linhas para o arroz de terras altas com arquitetura de planta moderna. Embrapa Arroz e Feijão-Comunicado Técnico (INFOTECA-E), 2003. Disponível em: http://www.cnpaf.embrapa.br/transferencia/info rmacoestecnicas/publicacoesonline/comunicadot ecnico_67.pdf. Acesso em: 01 nov. 2015.

EPAGRI. Síntese Anual da Agricultura de Santa Catarina 2014-2015. 2015. Disponível em: http://www.epagri.sc.gov.br/?page_id=7473.

Acesso em: 07 nov. 2015.

KÖPPEN, W.; GEIGER, R. Klimate der Erde. Gotha: Verlag Justus Perthes, 1928.

OLIVEIRA, G. S. Efeito de densidade de semeadura no desenvolvimento de cultivares de arroz (Oryza sativa L.) em condições de sequeiro e irrigado por aspersão - análise comparativa de custos. 1994. (Trabalho Graduação: Faculdade de Engenharia de Ilha Solteira), Universidade Estadual Paulista, 45p. 1994. https://doi.org/10.17801/01013122/rbs.v20n2p187-194

OLIVEIRA, G. S.; ARF, O.; SÁ, M. E.; RODRIGUES, R. A. F. Efeito de espaçamentos e densidades de semeadura no comportamento de cultivares de arroz de sequeiro, irrigados por aspersão. Revista Brasileira de Sementes, v. 20, n. 2, p. 187-193, 1998.
SANTOS, A. B. Comportamento de cultivares de arroz de sequeiro em diferentes populações de plantas, com e sem irrigação suplementar. 1990. 94f. Tese (Doutorado em Fitotecnia) - Escola Superior de Agricultura Luiz de Queiroz, Universidade de São Paulo, Piracicaba. 1990.

SANTOS, P.G.; DE CASTRO A. P.; SOARES A. A.; CORNELIO, V. M. O. Efeito do espaçamento e densidade de semeadura sobre a produção de arroz de terras altas irrigado por aspersão. Ciência e Agrotecnologia, v. 26 n. 3, p. 480-487, 2002.

SANTOS, G. R., NETO, M. D. D. C., RODRIGUES, A. C., BONIFACIO, A., KORNDORFER, G. $\mathrm{H}$. Fertilização silicatada e nitrogenada no controle da brusone do arroz em sistema irrigado. Revista Caatinga, v. 27, n. 4, p. 103-108, 2014.

SOSBAI. Arroz irrigado: recomendações técnicas da pesquisa para o sul do Brasil. Congresso Brasileiro de Arroz Irrigado. Reunião da Cultura do Arroz Irrigado. Porto Alegre: SOSBAI, 188p. 2010.

SOUZA, A. F.; AZEVEDO, S. M. Influência do espaçamento e densidade de semeadura na cultura do arroz sob irrigação por aspersão (pivô central). Pesquisa Agropecuária Brasileira, v. 29, n. 12, p. 1969-1972, 1994.

STONE, L. F.; PEREIRA, A. L. Sucessão arroz-feijão irrigados por aspersão: efeitos de espaçamento entre linhas, adubação e cultivar na produtividade e nutrição do arroz. Pesquisa Agropecuária Brasileira, v. 29, n. 11, p. 17011713, 1994.

UTUMI, M. M. Sistema de produção de arroz de terras altas. 4. ed. Porto Velho, RO: Embrapa Rondônia, 2008. 33 p.

Recebido para publicação em 03/03/2018

Revisado em 19/08/2018

Aceito em 22/08/2018 